\title{
Time-Varying Conditional Co-movement between Inter- Sector Stock Returns: Evidence from Ghana Stock Market
}

\author{
T. Appiah, and A. Forson
}

\begin{abstract}
Investors generally exhibit home bias with regards to their investment destinations. To diversify their portfolio, such investors invest in different sectors within the domestic economy. However, such behaviour could be counterproductive in periods of increased co-movement of assets returns. In this paper, we examine the inter-sector stock return co-movement among the major sectors of the Ghanaian economy with the view to shedding some light on the nature of assets return correlations and its implications for portfolio diversification. A sample of 332 weekly observations of stock returns of five major sectors within the Ghanaian economy is used to undertake the analysis. Dynamic Conditional Correlation - Generalized Autoregressive Conditional Heteroscedasticity (DCC-GARCH) techniques are applied to the weekly stock return series from January 2010 to June 2017. The DCC-GARCH model was estimated with correlation targeting and asymmetric DCC. We find dynamic conditional correlation among stock returns of all the sectors, implying that the correlation between the sector returns is time-varying. This result challenges the assumption of constant correlation among stock returns of different sectors in the domestic markets. We also find that the conditional correlation between returns of the various sectors ranges from 0.234 to 0.998 , which indicates medium to very high interdependence among the stock returns. Based on the result of this study, we propose that fund managers and investors should not limit their diversification strategies to inter-sector investments since in periods of uncertainty, the ability of the investor to enjoy diversification benefits is seriously undermined.
\end{abstract}

Index Terms - Credit risk; Co-movement; Ghana Stock Exchange; Panel Co-integration.

\section{INTRODUCTION}

The groundbreaking work of [1] represents the foundation on which modern portfolio theory (MPT) is built. The theory, which is often described as the mean-variance theorem, uses the risk-return tradeoff to determine the investor's optimal portfolio. The MPT posit, among others, that investors can achieve some level of risk reduction by spreading their investment across different sectors, different countries, and different asset classes. However, investing in different sectors or different asset classes in the same economy requires the investors to understand the extent to which these returns correlate or move together in the long-run. This claim is supported by [2] who opined that investors who are minded to examine the interaction between the various securities in their portfolio of investment are better placed to understand the level of co-movement between the various securities and therefore, select the right combination of securities that will minimize their risk. In other words, the mean-variance theory stipulates that assessing the nature of the co-movement between securities in a given portfolio can go a long way to help investors build a well-diversified portfolio that can minimize the level of risk faced by these investors. By spreading their investment across different sectors, securities, and regions, investors can build a well-diversified portfolio aimed at minimizing the total risk faced. Since there are benefits to be derived from diversification, understanding the level of correlation or co-movement among various securities is of a striking important to investors and fund managers.

Diversification across a variety of countries offer benefits in terms of risk mitigation arising from the low correlation between asset returns [3], [4]. In theory, it is expected that owning foreign assets would give investors greater diversification benefits as their prices are often less correlated and determined by different fundamental economic factors [5], [6]. However, recent studies such as [7]-[9] have observed that the advantages of foreign diversification are slowly diminishing due to financial sector globalization and increased market integration. Studies have also shown that in terms of their investment decisions, investors are likely to demonstrate a home-bias. A cursory analysis of the literature on diversification shows that investors tend to hold predominantly domestic asset dominated portfolios [10] [12]. Whereas diversification across sectors within the domestic market may reduce portfolio risks as a result of the unique characteristics of each sector, investors holding local assets across multiple sectors may be exposed to high risks in periods of increased co-movement between assets held locally, which may erase the benefits of cross-sector diversification [13]. The extent to which local diversification protects investors from periods of uncertainties requires empirical studies to unravel. The main focus of this paper is to analyze the co-movement between major economic sectors in Ghana using a dynamic framework.

Our paper is different a number of ways. First, it uses the DCC-GARCH model developed by [14] to measure and analyze the dynamic conditional correlations among stock

Published on July 5, 2020.

T. Appiah, Ghana Technology University College, Ghana

(corresponding e-mail: appiah.thomas225@gmail.com)

A. Forson, Civil Service, Ghana.

(e-mail: abednegoforson ${ }^{\circledR}$ yahoo.com) 
returns. To the best of our knowledge, the research is among the few studies to apply the DCC-GARCH model to investigate the dynamic conditional correlation of company stock returns. The DCC-GARCH model is able to investigate correlation between asset returns and predict conditional variances using robust and time-variant correlation estimate. Furthermore, whereas studies such as [15]-[18] have explored inter-sector stock return co-movement, these studies have mainly focused on developed and emerging market with little focus on developing countries. Again, the majority of the studies on stock return co-movement and spillover effects have mainly focused on inter-regional or inter-country comovement and have paid less attention to inter-sector comovement in a single country.

The main purpose of this paper is to investigate the dynamics of the stock-return co-movement of the major sectors of the Ghanaian economy with the view to understanding the potential benefits associated with intersector stock diversification. In achieving this, we investigate whether co-movement between asset returns among these sectors are time-varying or constant. We also investigate the existence of volatility spillovers between the major sectors of the economy. Understanding the inter-sector correlation of stock return could aid investors and investment institutions to device portfolio strategies that may optimize their portfolio return. It is even more important for fund managers and investors who rely on static and past correlational estimates as a guide in forming a diversified portfolio. Also, the study adds to the literature by showing how stock returns among major sectors of the Ghanaian economy are correlated and serves as important reference material for students and future researchers.

The rest of the paper is organized as follows: Section two presents theoretical and empirical literature on the subject, outlining the various concepts and ideas regarding asset return co-movement. Section three describes the data and methodology adopted in the study. Section four presents the results of the study and discuss its findings. Finally, section five presents the conclusion and policy implications of the study.

\section{LITERATURE REVIEW}

\section{A. The Co-movement of Asset Returns}

Asset return co-movement has been defined by [19] from two different perspectives. These are pricing and statistical perspectives. Jorion and Schwartz [20] define asset return comovement from the asset pricing perspective by explaining that stock return co-movement occurs when the same riskadjusted return is earned by investors when they invest in similar financial instrument across different markets. On the other hand, [21] define market co-movement from a statistical perspective by indicating that market integration occurs when stock markets across different jurisdictions tend to co-move in the long run. When the markets are highly integrated or the level of co-movement increases, there is a decrease in the diversification benefits that can be enjoyed by investors. Xiang, Wang, and Hao [22] have observed that co-movement of asset returns shows the degree to which the prices of various stocks or markets correlate or move together. The authors further explain that, when asset returns are closely related, they have a common long-term equilibrium association. Poldauf [23] also describes the co-movement of asset returns as the propensity of asset prices to move together in such a way that their values are positively correlated or linked.

The causes of asset return-movement have been categorized into fundamental factors and non-fundamental economic factors. According to [24] and [25], in a frictionless marketplace dominated by rational investors, price correlations reflect shifts in fundamental economic values such as inflation, interest rate exchange levels, and trade prices, among others. The economic fundamental view is that companies in the same sector or country should show higher asset-return co-movements as they share similar economic fundamentals [25]. Whereas [25] believe that economic fundamentals are the only cause of asset return comovement among stocks, [26] explain that economic factors alone are not enough to explain stock return co-movement. According to the authors, the assumption of frictionless market and rational investors are not sustainable in most markets and therefore non-economic factors should be considered when examining the causes of asset return comovement. According to [27] fundamental theory of comovement is rendered non-functional when there are irrational investors and imperfect markets. Therefore, the author believes that considering non-fundamental factors is also important. Whereas the focus of this paper is not to investigate the causes of asset return co-movement, it examines the nature of co-movement of asset returns among different sectors of the economy of Ghana and the possible diversification potentials for investors.

\section{B. Empirical Literature}

The extent to which financial markets relate to each other has been studied extensively, albeit with contrasting results. Various contexts have been applied to study stock return comovement in the extant literature. According to [28], the contexts within which these studies have been carried out can be grouped into two. The first is a cross-sector investigation of asset return co-movement, where the level of co-movement among the stock returns of selected sectors in a single economy is assessed. The second is cross-country comovement analysis, where the level of cointegration and correlation among stocks in different countries and regions are examined. Whereas some studies have found strong interrelationship between stock markets, others have reported week relationship. For instance, [29] have observed that there is a weak interdependence between stock markets in most African markets, which suggest that investors can take advantage of this weakness to diversify their portfolio. In contrast, the study by [30] has observed that there is significant interdependent among Asian markets. Specifically, the study found a very high interdependence among the Japanese and Chinese markets. Also, studies such as [31] and [32] have identified strong cointegration among stocks in Asian markets, which makes the markets prone to negative shocks after a major financial crisis. Also, in a study undertaken by [33], the author investigated the co-movement of bond and stock returns among CIVETS countries which includes Colombia, Indonesia, Vietnam, Egypt, Turkey and 
South Africa. Using GARCH models, and applying the methodologies proposed by [34], [14] and [35], the findings of the study indicate that the correlation between the returns of bonds and stocks are time-varying and therefore cannot be said to be constant. Also, the result of the study revealed the returns of bond and stock among these CIVETS nations have volatility that exhibits positive asymmetry, indicating that both bonds and stocks respond unfavourably to bad news and less favourably to good news. Given the findings, the authors concluded that there are some diversification benefits to be obtained by investors when they spread their investment across the CIVETS nations. Also, [36] investigated stock return co-movement among German and selected international markets. The purpose of the investigation was to ascertain whether investors can enjoy diversification benefits associated with their investment in Germany and other international markets. Both DCC-GARCH and Wavelet analysis techniques were applied to estimate the dynamic correlation among the stock returns of these nations. Using market indices from Germany and five other markets, the study's result shows that there are significant differences in the co-movement dynamics among the selected countries. However, the study observed that across the selected countries it was clear that the correlation among stock returns is dynamic and changes over some time. In Botswana, [37] also examine inter-sector asset return co-movement among selected stocks in that country. The focus of the study was to determine the extent to which diversification benefits can be achieved by investors who diversify their portfolio of investment across different sectors of the economy. The result of the study revealed a week but positive correlation among the stock returns of the selected sectors, indicating that some level of diversification benefits can be achieved by investors who invest across these sectors. In a related study, [38] also investigated the dynamic correlation among nine Swedish companies from 1985 to 2003. Stock market data for the study period was employed to estimate the formulated correlation and regression models. Using linear multifactor models and Ordinary Least Square regression techniques, the result of the study shows the presence of excess co-movement among the selected sectors, indicating that it will be difficult for investors to identify their portfolio's optimal risk profile. Furthermore, a wavelet analysis of stock return co-movement among international markets was conducted by [39]. The use of the wavelet technique was to determine the correlation among the stock returns in a time-frequency space. Stock market data for four developed countries; namely, Germany, Japan, UK and the US were employed. The result of the study shows that while some diversification benefits can be derived from cross-border investments, the benefits will wane in the long run. In other words, the result observed that the diversification benefits from international investment are high at lower frequencies and low and higher frequencies. This result implies that in the long run, diversification benefits through international investment cannot be significantly achieved. The result of the study further found that the degree of correlation among the stock returns are time-variant and therefore it will be misleading to rely on constant co-movement when making investment decisions. In the United States, [40] also investigated the cross-correlation among banking stocks using 22 banks. The study had a single aim of investigating the extent to which these stock correlate over some time. Using GARCH models proposed by [41], the study found the stock return correlations exhibit positive trend, which indicates rising systematic risk over the period. Also, [13] examine the stock return co-movement among the largest economic sectors in South Africa to determine the extent to which investors can benefit from inter-sector diversification within South Africa. The study applied the DCC-GARCH model to estimate the dynamic conditional correlation among the selected sectors. The result of the study also supported the results that found a dynamic correlation among stock returns. The study, therefore, found no evidence to support the constant co-movement among stock returns in South Africa. Das et al. [41] also investigated stock return co-movement among selected Asian and Oceania markets. The study had two objectives of assessing the co-movement among stock returns and to determine the volatility of stock returns associated with different time scales. The study sought to provide relevant information that may be crucial to the investor when constructing their diversified portfolios. Using data from selected markets such as Australia, Hong Kong, Japan, New Zealand, and Singapore, the result of the study shows that diversification benefits to be derived by investors in these markets are limited due to market integration and globalization. The authors also observed significant contagion and volatility spillover among the selected countries which supports the earlier assertion that diversification benefits cannot be achieved by investors in such markets.

Following the literature review, it is clear that despite the existence of some DCC-studies in different parts of the world, including Africa, few of these studies have exclusively examined the nature and structure of the inter-sector return co-movement or correlation in West Africa. A cursory perusal of the extant literature also indicates that there are generally few studies that apply Multivariate GARCH models to examine the dynamic correlation among domestic sectors and the nature of volatility spillovers among these sectors. It is, therefore, important for such research gaps to be bridged.

\section{Overview of the Stock Market in Ghana}

Ghana stock exchange (GSE) was established in 1989 as a company limited by guarantee. However, the actual launching and operation of the stock exchange began in 1991. Companies that were first listed on the exchange include Standard Chartered Bank, Uniliver Ghana Limited, Guinness Ghana Breweries Ltd., Fan Milk Limited. PZ Cussons Ghana Ltd. Companies are accepted to list on the exchange based on well-defined criteria such as profitability, management efficiency, the number of years in existence, and capital adequacy. Since its inception, The GSE all-share index has been used as the main index to measure the performance of the exchange. Since its establishment, the GSE has supported investments, helped to develop financial products, created public awareness about investment, and supported investor education. It has also provided an avenue for businesses and the government to raise long-term capital to support their operations [42]. It has also encouraged investment among individuals and provided an opportunity for investors to diversify their investment interests [43]. Despite the challenges faced by the GSE which includes, low liquidity, 
small market size and low market participation, it has chalked some enviable successes since it began operations [44]. The GSE started very well and posed impressive performance in its early years. Four years after its existence, it was recognized as the sixth-best performing index among emerging stock markets. In 1994, the GSE all-share index posed an impressive capital appreciation of $116 \%$. Also, in 2004 the GSE was adjudged the best performing market across the African continent in terms of the return performance. After the listing of Tullow oil, one of the most successful oil exploration firms in the world, the Ghana stock exchange became the third-largest market in sub-Saharan Africa after the South African Stock Exchange and the Nigerian stock exchange [45]. As at the end of 2019, the GSE had 37 companies listed, with 42 equities. In addition to the equities, two corporate bonds are also listed. The companies listed on the GSE can generally be grouped into five sectors. These include Basic material, consumer goods, oil and gas, health, and finance. Currently, the GSE is undergoing some form of a facelift as part of the country's quest to improve the capital market. Plans are underway to introduce electronic trading to make the exchange more efficient. The Central bank of Ghana (BOG) also plans to introduce mutual fund and municipal bond markets to enhance investment on the Exchange.

\section{METHODOLOGY}

\section{A. Data}

Data set for the study consist of average weekly stock returns of the five main sectors under the GSE. These sectors include Health (HT), Consumer Goods (CG), Basic Materials $(\mathrm{BM})$, Financial $(\mathrm{FN})$, and Oil $\wedge$ Gas $(\mathrm{OG})$. Data were obtained from the official website of the Ghana Stock Exchange over a period of 7 years (From 2010 to 2016). The calculation of the weekly stock returns was done based on the weekly compound basis. The weekly return $r_{t}$ is calculated using the equation:

$r_{t}=\ln \left(\frac{P_{t}}{P_{t-1}}\right) * 100$

where, $P_{i j, t}$ and $P_{i j, t-1}$ are the price index of week $t$, and $t-$ 1 respectively. $\ln$, represents the natural logarithm.

\section{B. Econometric Model}

Borrowing from the study by [14], we examine the intersector stock return co-movement dynamics using DCCGARCH model. According to [14] the estimation of the DCC-GARCH model can be simplified into two main steps. The first step is achieved by estimating the univariate GARCH models for each of the residual series. In the second step, the estimated models in step one are transformed to estimate the parameters of the dynamic correlation.

To estimate the time-varying conditional volatility of returns on stock $i$ at a given time, $t$, (represented by, $r_{i, t}$ ), the following GARCH model is applied:

$h_{i, t}=\omega_{i}+\sum_{j=1}^{p} \alpha_{i j} \varepsilon_{i, t-j}^{2}+\sum_{j=1}^{q} \beta_{i j} h_{i, t-j}$
$i=1,2, \ldots, \mathrm{k}$
From this equation, $\varepsilon_{t}=\eta_{t} \sqrt{h_{i t}}$ is designated as the error term of the model, $\eta_{t}$ is a sequence of independently and identically distributed random variables, which has zero mean with a variance of 1 .

$h_{i, t}$ is the conditional variance of returns on stock $i$ at time $t$, and $\alpha_{i}$ and $\beta_{i}$ are ARCH and GARCH effects respectively (Manera, et al. 2006). The second stage of the estimation characterizes $\varepsilon_{t}$ as a diagonal matrix and a time-varying correlation matrix is expressed as:

$$
\begin{array}{r}
r_{i, t} \mid \psi_{t-1} \approx N\left(0, H_{t}\right), \quad H_{t} \equiv D_{t} R_{t} D_{t} \\
\varepsilon_{t}=D_{t} \eta_{t}, E_{t-1}\left(\varepsilon_{t}^{\prime}\right)=R_{t}
\end{array}
$$

Where $H_{t}$ represents the covariance matrix, $r_{i, t}$ which is normally distributed with a mean of zero, $\psi_{t-1}$ denotes information set available at $\mathrm{t}-1$ and $\mathrm{D}_{\mathrm{t}}$ is a $\mathrm{k} \mathrm{x} \mathrm{k} \mathrm{diagonal}$ matrix of time-varying residuals obtained from step 1 , with $\sqrt{h_{i, t}}$ on the $\mathrm{i}^{\text {th }}$ term, given as:

$$
D_{t}=\left(\begin{array}{cccc}
\sqrt{h_{11, t}} & 0 & \cdots & 0 \\
0 & \sqrt{h_{22, t}} & \cdots & \ldots \\
\cdots & \cdots & \cdots & 0 \\
0 & \cdots & 0 & \sqrt{h_{m n, t}}
\end{array}\right)
$$

The residuals are further standardized and applied to (2) $R_{t}$ is a k x k time-varying matrix that can be expressed

$R_{t}=\left(\operatorname{diag}\left(Q_{t}\right)\right)^{-1} \cdot Q_{t} \cdot\left(\operatorname{diag}\left(Q_{t}\right)\right)^{-1}$

Thus, the DCC structure can be expressed as follows:

$Q_{t}=\left(1-\delta_{1}-\delta_{2}\right) \bar{Q}+\delta_{1}\left(\varepsilon_{t-1} \varepsilon_{t-m}^{\prime}\right)+\delta_{2} Q_{t-n}$

$\bar{Q}$ denotes the covariance of standard errors derived from step 1. Standardizing and using the residuals from step 1, we obtain the matrix:

$R_{t}=Q^{*-1} Q_{t}{ }^{*-1} ; Q_{t}{ }^{*}$ is a diagonal matrix consisting to the squared root of diagonal element of $Q_{t}$ and is represented as:

$Q^{*}=\left(\begin{array}{cccc}\sqrt{q_{11}} & 0 & \cdots & 0 \\ 0 & \sqrt{q_{22}} & \cdots & 0 \\ \cdots & \cdots & \cdots & \cdots \\ 0 & 0 & \cdots & \sqrt{q_{k k}}\end{array}\right)$

The element, $R_{t}$ can be estimated using $\rho_{12, t}=\frac{q_{12, t}}{\sqrt{q_{11,} q_{22, t}}}$, where $\rho_{12, t}$ is the conditional Co-variances of the standardized residuals.

\section{RESULTS AND DISCUSSIONS}

\section{A. Description of Data}

The descriptive statistics of the data is presented in Table 1. These include the mean, standard deviation, skewness, 
kurtosis, Jarque-Bera (J-B) test statistics, and p-value for normality hypothesis testing, and J-B test. These descriptive statistics are calculated based on logarithmic stock indices of the selected sectors. The Kurtosis values for all the sectors exceeds 3, indicating that the returns are non-normal. According to [46] for data to display a semblance of normality, the J-B statistic or coefficient should be closer to zero. The high J-B values, as shown in Table 1, indicates that the data is not normally distributed. The lack of normality in the data is not surprising since in most cases financial time series data is noted for exhibiting non-normality [13] [47]. It is also clear from the descriptive statistics that the Standard deviation values, relative to the means, are quite high, indicating high volatility in the returns of the selected stocks.
The average returns for Consumer Goods (CG) and Oil \& Gas (OG) are negatively skewed, which implies that the distribution of these assets is non-normal and more skewed towards the left.

The remaining three sectors have positive skewness, which indicates that there is a non-normal distribution of these assets and more skewed toward right than a normal distribution. Again, it can be observed that the returns of Health and Oil \& Gas show the highest and lowest skewness levels respectively. It further means that Oil \& Gas has a statistically negative skewness as against a normal distribution of zero which indicates that the data are spread around the left side than the right

TABLE 1: Descriptive Statistics OF STUdy VARIABLES

\begin{tabular}{cccccc}
\hline & BM & CG & FN & HT & OG \\
\hline Mean & 0.001279 & 0.001120 & 0.003194 & 0.008130 & 0.000566 \\
Median & 0.000000 & 0.000901 & 0.000548 & 0.000000 & 0.000568 \\
Maximum & 1.487979 & 0.063937 & 0.081120 & 2.021392 & 0.068135 \\
Minimum & -0.839705 & -0.229668 & -0.086486 & -0.190075 & -0.637392 \\
Std. Dev. & 0.111448 & 0.017854 & 0.018785 & 0.133687 & 0.037655 \\
Skewness & 5.811479 & -7.619788 & 0.776691 & 12.79732 & -14.61475 \\
Kurtosis & 106.6182 & 94.16952 & 7.110389 & 179.3264 & 249.0723 \\
Jarque-Bera & 150846.6 & 118549.8 & 267.9026 & 440476.7 & 852007.7 \\
Probability & 0.000000 & 0.000000 & 0.000000 & 0.000000 & 0.000000 \\
Observations & 332 & 332 & 332 & 332 & 332 \\
\hline
\end{tabular}

Source: Author's Computation Using Eviews.

\section{B. Preliminary test for $\operatorname{GARCH}(1,1)$}

To determine the suitability of the data for DCC-GARCH analysis, a number of preliminary tests were conducted. These include unity root, volatility clustering, and the ARCH effect. [14] posit that to avoid bias and ensure the reliability of financial data, the dataset must be stationary. Also, [48] and [49] have observed that a typical time-series financial data must exhibit volatility clustering, where "large changes in the data series is accompanied by large changes and small changes accompanied by corresponding small changes".

To proceed successfully with the DCC GARCH model, we first examined the presence or otherwise of unit root in the stock returns of the sectors. Two main unit root tests were employed. These are Augmented Dickey Fuller test (ADF) and Kwiatkowski- Phillips-Schmidt-Shin (KPSS) unit root tests. With the ADF unit root test, the null hypothesis of unit root is compared with the alternative hypothesis of no unit root. The null hypothesis is rejected when the ADF test statistics is significant at $5 \%$ or $1 \%$ level. Otherwise, we fail to reject the null hypothesis. With the KPSS unit root test, the null hypothesis of no unit root (i.e time series is stationary) is compared with the alternative hypothesis of unit root. The null hypothesis is rejected in favour of the alternative hypothesis when the p-value of the KPPS test statistic is greater than 5\% [50]. The result of the ADF and KPSS unit root tests is shown in Table 2.

TABLE 2: UNIT ROOT TEST

\begin{tabular}{ccccc}
\hline Sectors & $\begin{array}{c}\text { ADF Test (a } \\
\text { constant and } \\
\text { trend) }\end{array}$ & $\begin{array}{c}\text { ADF Test (a } \\
\text { constant) }\end{array}$ & $\begin{array}{c}\text { KPSS test } \\
\text { constant }+ \\
\text { trend) }\end{array}$ & $\begin{array}{c}\text { KPSS test } \\
\text { (constant) }\end{array}$ \\
\hline BM & $-8.905 * *$ & $-8.909 * *$ & 0.116 & 0.173 \\
CG & $-12.147 * *$ & $-12.140^{* *}$ & 0.080 & 0.137 \\
FN & $-10.175^{* *}$ & $-9.950^{* *}$ & 0.108 & 0.343 \\
HT & $-11.614^{* *}$ & $-11.626^{* *}$ & 0.065 & 0.080 \\
OG & $-16.959^{* *}$ & $-16.829 * *$ & 0.047 & 0.302 \\
\hline
\end{tabular}

** Significant at $1 \%$ level.

Source: Author's Computation Using Eviews.

The result indicates that all the return series are stationary, indicating that there is no unit root in the series and, therefore, can be used to conduct DCC GARCH analysis.

Another preliminary test required to perform GARCH analysis is volatility clustering in the return series. According to [49] the presence of volatility clustering is important for analyzing GARCH models. Volatility clustering becomes evident when plotted residuals indicate a pattern such that large volatilities are correspondingly followed by large volatilities, whereas small volatilities are also accompanied by volatilities over some time [49]. Volatility clustering explains the tendency for financial time series data "tends to be followed by large changes, of either sign, and small 
changes tend to be followed by small changes". Figure 1 depicts the pattern of the returns over a period. A cursory observation shows the presence of volatility clustering, where large returns are accompanied by large ones and vice-versa. The result, therefore, supports the use of GARCH for further investigation.

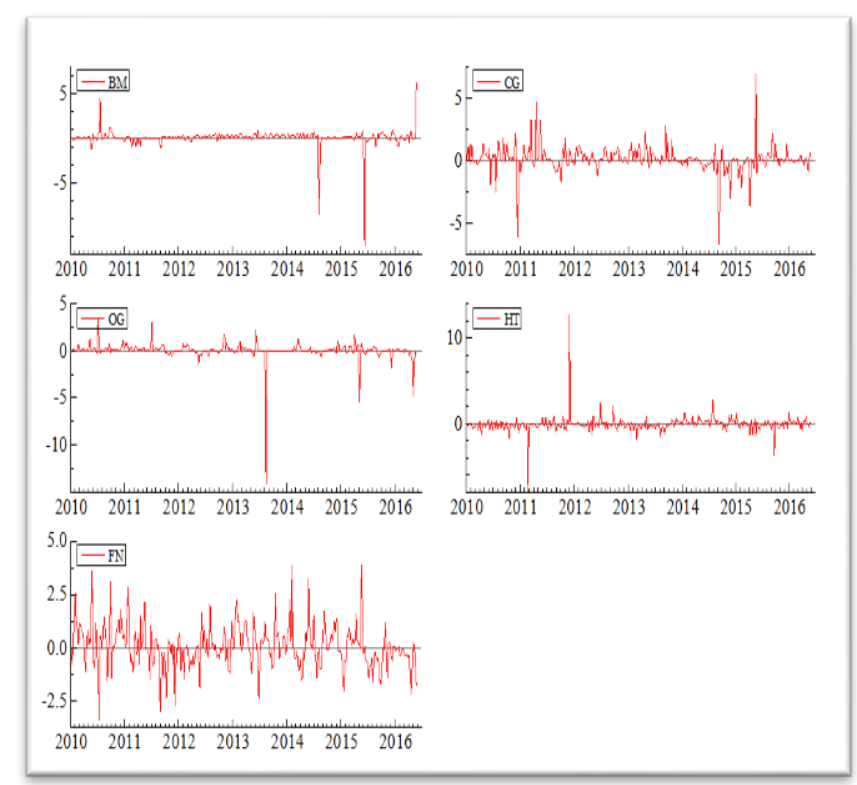

Fig. 1. Test of volatility clustering. Source: Author's Computation Using Eviews.

A time series is described as having ARCH effect when it exhibits conditional heteroscedasticity or autocorrelation in the squared series. A time series must exhibit ARCH effect to make the result reliable and unbiased. In testing for the $\mathrm{ARCH}$ effect, the null hypothesis of the presence of ARCH effect is tested against the alternative hypothesis of no $\mathrm{ARCH}$ effect. The ARCH-LM was used to examine ARCH effect in sector returns. In all the return series, we fail to reject the null hypothesis and conclude that there is a presence of $\mathrm{ARCH}$ effect. This makes it suitable for GARCH family of models, such as DCC GARCH to be applied. To determine the presence or absence of serial correlation based on Ljung-Box test [48], the correlogram of the standardized residuals were observed. Using 24 lags for the analysis, the Q-stats are observed to be highly insignificant (using a 95\% confidence interval). This result clearly shows that the returns are free from serial correlation.

We also test the long run-equilibrium relationship between the sector returns using the Johansen [51] cointegration test. The purpose of the test is to determine whether sector returns are cointegrated or move together in the long -run.

From the results presented in Table 3, it can be observed that there exists at least one co-integration relationship with regards to the sector returns. The establishment of cointegration relationship further supports the suitability of DCC-GARCH model for the analysis.
TABLE 3: JOHANSEN COINTEGRATION TEST RESULTS

\begin{tabular}{|c|c|c|c|c|c|}
\hline $\begin{array}{l}\text { Data } \\
\text { Trend: }\end{array}$ & None & None & Linear & Linear & Quadratic \\
\hline $\begin{array}{l}\text { Test } \\
\text { Type }\end{array}$ & $\begin{array}{c}\text { No } \\
\text { Intercept } \\
\text { No } \\
\text { Trend }\end{array}$ & $\begin{array}{c}\text { Intercept } \\
\text { mNo } \\
\text { Trend }\end{array}$ & $\begin{array}{c}\text { Intercept } \\
\text { No } \\
\text { Trend }\end{array}$ & $\begin{array}{c}\text { Intercept } \\
\text { Trend }\end{array}$ & $\begin{array}{c}\text { Intercept } \\
\text { Trend }\end{array}$ \\
\hline Trace & 5.0 & 5.0 & 5.0 & 5.0 & 5.0 \\
\hline Max-Eig & 5.0 & 5.0 & 5.0 & 5.0 & 5.0 \\
\hline
\end{tabular}

Source: Author's Computation Using Eviews.

\section{Analysis of DCC-GARCH Model}

In Table 4, the overall model exploring the dynamic conditional correlation between the five sectors is presented. Three different DCC $(1,1)$ models were estimated with different assumptions. The results for correlation targeting and asymmetric DCC are reported. The correlation targeting estimation assumes either Multivariate Normal distribution or Student's- $t$, whereas the asymmetric DCC assumes a normal distribution. The estimate $\theta 1$ represents the impact of past shocks on current conditional correlations and $\theta 2$ represents the impact of previous dynamic conditional correlations. The result shows that $\theta 1$ is significant in all instances, where $\theta 2$ is statistically insignificant. This indicates that the conditional correlations are not constant. In all cases, the stability condition is met as the sum of $\theta 1$ and $\theta 2$ is always less than 1 .

TABLE 4: DCC $(1,1)$ MODELS

\begin{tabular}{lccc}
\hline & \multicolumn{2}{c}{ Correlation targeting } & $\begin{array}{c}\text { Asymmetric } \\
\text { DCC }\end{array}$ \\
\hline Parameter & Normal & Student's-t & Normal \\
& distribution & dist & distribution \\
$\boldsymbol{\theta 1}$ & $0.152^{* *}$ & $0.369 * * *$ & $0.3194 * * *$ \\
& {$[0.010]$} & {$[0.000]$} & {$[0.000]$} \\
$\boldsymbol{\theta 2}$ & 0.200 & 0.0148 & 0.272 \\
& {$[0.365]$} & {$[0.655]$} & {$[0.104]$} \\
$\boldsymbol{\theta 1}+\boldsymbol{\theta 2}$ & 0.353 & 0.383 & 0.592 \\
Log-likelihood & 3679.746 & 2649.037 & 3683.283 \\
Akaike info criterion & 21.908 & -15.705 & -21.833 \\
Schwarz criterion & -21.542 & -15.317 & -21.284 \\
Hannan-Quinn criterion & -21.762 & -15.550 & -21.614
\end{tabular}

** and $* * *$ represents rejection at $5 \%$ and $10 \%$ significance levels respectively,

Source: Author's computation using Eviews,

Table 5 presents the DCC-GARCH estimates between the five major sectors of the Ghanaian economy. The estimate $\theta 1$ represents the impact of past shocks on current conditional correlations, and $\theta 2$, the impact of previous dynamic conditional correlations. From the results, it can be observed that the conditional correlation of the majority of the sector pairs shows a significant variation over time. Also, all the parameters are higher than zero. Furthermore, the sum of theta 1 and theta 2 is less than $1(\theta 1+\boldsymbol{\theta} 2 \leq 1)$, which is an important requirement for the appropriateness of DCCGARCH. Except for the sector pairs CG-OG, and FN-HT, all the other pairs report $\theta 1$ being highly significant ( $\mathrm{p}$-value $\leq 0.05$ ). The results also indicate that $\theta_{2} \geq \theta 1$ in all sector pairs, which suggest that the impact of previous dynamic conditional correlations on the current dynamic correlations is more severe than the impact of past shocks on current conditional correlations. Furthermore, it is observed that 
$\theta 1+\mathrm{d} \theta 2$ is larger than zero which implies that conditional correlations are time-varying and not constant. The sum of the parameters, $\theta 1$ and $\mathrm{d} \theta 2$ in all the sector pairs is close to 1 , indicating that there is high persistence in conditional variances, which achieves mean-reverting at a slow pace [52].

The analysis of the DCC-GARCH Model provides an important insight into the nature of the co-movement between the returns of the various sectors and its potential diversification implications for investors. The results indicate that the dynamic conditional correlations between the standardized shocks for each pair of returns is timevarying, and intermittently switches from positive to negative. This result implies that it is misleading and empirically incorrect to assume that conditional correlation for all shocks to return is constant. The non-constant nature of the correlation between returns over time may be attributed to the changing nature of the economic and political environment. This finding implies that relying on static or constant correlation estimates to make diversification decisions within the Stock market of Ghana may be misleading. This finding is in agreement with the findings [13] and [36] who suggested the use of static or constant comovement measures to assess the diversification potential of securities within a portfolio may not be accurate as a result the volatility in the macroeconomic landscape. The results also imply that investors and fund managers should not rely on constant correlation estimates to make investment diversification decisions.

TABLE 5: DCC-GARCH PARAMETER ESTIMATES

\begin{tabular}{|c|c|c|c|c|c|c|c|c|c|c|}
\hline \multirow[t]{2}{*}{ Sectors } & \multicolumn{2}{|c|}{$\mathrm{BM}$} & \multicolumn{2}{|c|}{ CG } & \multicolumn{2}{|c|}{$\mathrm{FN}$} & \multicolumn{2}{|c|}{ OG } & \multicolumn{2}{|c|}{ HT } \\
\hline & $\theta 1$ & $\theta 2$ & $\theta 1$ & $\theta 2$ & $\theta 1$ & $\theta 2$ & $\theta 1$ & $\theta 2$ & $\theta 1$ & $\theta 2$ \\
\hline BM & & & $\begin{array}{c}0.123 \\
{[0.000]}\end{array}$ & $\begin{array}{c}0.876 \\
{[0.000]}\end{array}$ & $\begin{array}{c}0.678 \\
{[0.000]}\end{array}$ & $\begin{array}{c}0.299 \\
{[0.002]}\end{array}$ & $\begin{array}{c}0.124 \\
{[0.000]}\end{array}$ & $\begin{array}{c}0.875 \\
{[0.000]}\end{array}$ & $\begin{array}{c}0.203 \\
{[0.000]}\end{array}$ & $\begin{array}{c}0.795 \\
{[0.000]}\end{array}$ \\
\hline CG & & & & & $\begin{array}{l}-0.016 \\
{[0.000]}\end{array}$ & $\begin{array}{c}0.754 \\
{[0.000]}\end{array}$ & $\begin{array}{c}0.248 \\
{[0.100]}\end{array}$ & $\begin{array}{c}0.224 \\
{[0.400]}\end{array}$ & $\begin{array}{l}-0.008 \\
{[0.045]}\end{array}$ & $\begin{array}{c}0.956 \\
{[0.000]}\end{array}$ \\
\hline FN & & & & & & & $\begin{array}{c}-0.016 \\
{[0.000]}\end{array}$ & $\begin{array}{c}0.751 \\
{[0.000]}\end{array}$ & $\begin{array}{c}-0.006 \\
{[0.690]}\end{array}$ & $\begin{array}{c}0.816 \\
{[0.234]}\end{array}$ \\
\hline OG & & & & & & & & & $\begin{array}{c}-0.011 \\
{[0.000]}\end{array}$ & $\begin{array}{c}0.988 \\
{[0.000]}\end{array}$ \\
\hline HT & & & & & & & & & & \\
\hline
\end{tabular}

P-values in parenthesis.

Source: Author's Computation Using Eviews

Figure 2 and 3 also presents the conditional covariance and the conditional correlation of the sector returns respectively. The covariance depicts the co-movement of the volatilities of the sectors. It can be observed that the conditional covariance are also time-dependent as displayed in the volatile nature of the plots. The estimates have switched from low (high) to high (low) and sometimes from negative (positive) to positive (negative). In Figure 3 we observe the nature of the dynamic correlation of the sector return. The result further confirms the earlier results that correlation between the inter-sector returns are not constant but fluctuates over time, indicating dynamic co-movement among the sector returns.

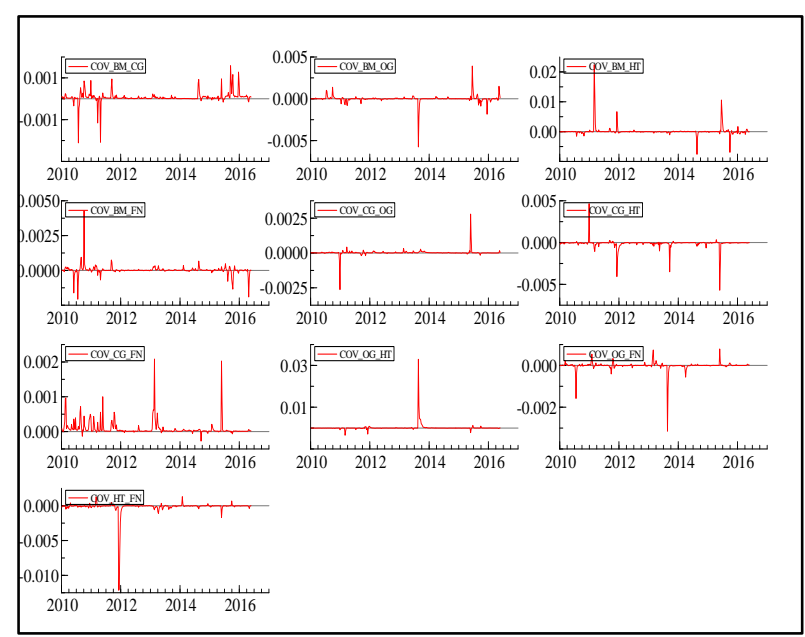

Fig. 2. Conditional Covariance between the inter-sector stock returns. Source: Author's Computation Using Eviews

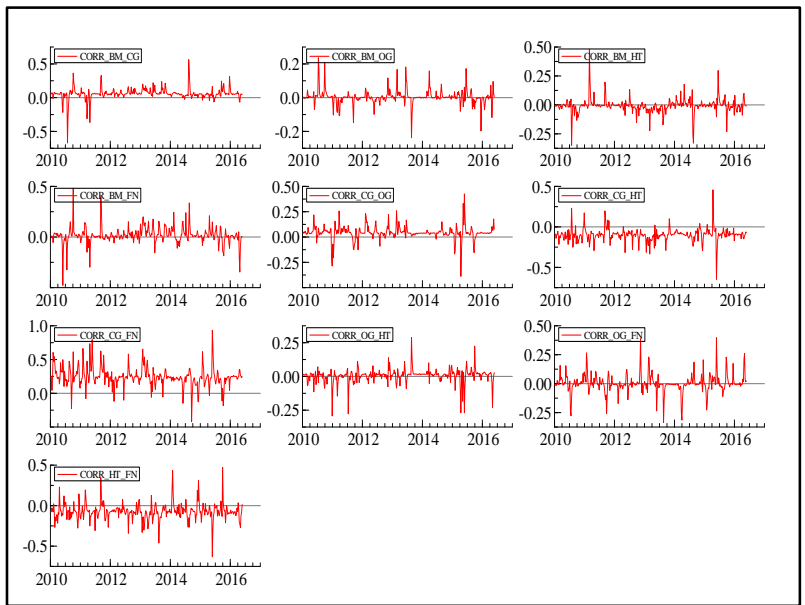

Fig. 3: Conditional Correlation between the inter-sector stock returns. Source: Author's Computation Using Eviews.

\section{CONCLUSION}

It is widely documented in the financial and investment literature that investors naturally exhibit home-bias when selecting their investment destinations. Put differently, investors naturally prefer to invest across different sectors domestically rather than spreading their investment globally. This behaviour is likely to expose such investors to significant risk in periods of increased co-movement between assets held domestically across different sectors in their portfolio. The possible diversification benefits associated 
with investing in different sectors within a domestic economy may be eroded in periods of high asset return co-movement. Against this backdrop, this paper explored the co-movement dynamics of assets returns across the major sectors of the Ghanaian economy. The purpose of the paper is to highlight the inter-sector diversification potential to aid investors and fund managers in their investment decisions. Specifically, the study sought to (1) examine whether the return co-movement between the five major sectors of the Ghanaian economy is time-varying or constant, and (2) investigate the existence of possible volatility spillovers between these sectors.

The DCC-GARCH model, which was popularized by [14] was applied to investigate the nature of the co-movement (correlation) between the sectors. The important characteristics of the return series such as stationarity, volatility clustering and $\mathrm{ARCH}$ effect were examined to determine the suitability of the data for the DCC-GARCH analysis. The result indicates high levels of dynamic conditional correlation among stock reruns of the companies in all the sectors, implying that the correlation among the sector returns is time-varying and not constant as assumed by some investors and fund managers. The study further found that both the previous dynamic conditional correlations and past shocks have a significant impact on current conditional correlations. However, the results show that the impact of previous dynamic conditional correlations on the current dynamic correlations is more severe than the impact of past shocks on the current conditional correlation. The study further observes that there is high persistence in conditional variances which achieves mean-reverting at a slow pace. The result of the dynamic conditional correlations and conditional co-variances indicate significant volatility in the stocks returns of the selected sectors. The study recommends that fund managers and investors should not limit their diversification strategies to inter-sector investment since inter-sector diversification will not lead to significant improvement in their portfolio's risk-return profile.

The study provides some insight into inter-sector stock return co-movement and how it could impact on portfolio diversification. The result is beneficial for multinational companies and fund managers who are interested in building a well-diversified portfolio to minimize potential risk. It also provides opportunities for government to introduce macroeconomic interventions that will minimize financial distress within the economy. Finally, the study helps individual investors in constructing a well-diversified portfolio that will enhance their returns and minimize risk.

Whereas the result obtained from this study provides some insight into the nature of inter-sector stock returns, it must be applied with some caution. Data for the study were sampled from selected companies in Ghana and therefore the findings cannot not be easily generalized to cover all other countries. Future empirical studies may expand the existing knowledge in stock return co-movement by considering other developing countries. It is also worthy to note that this study mainly focused on the level of co-movement among the stock returns of selected sectors in Ghana. Issues relating to the sources of the co-movement was however not considered in this study. We therefore entreat future researchers to investigate the sources of stock return co-movement by considering both economic (fundamental) and non-economic (sentimental) sources.

\section{REFERENCES}

[1] H. Markowitz, "Portfolio selection", Journal of Finance. Vol. 7, No. 1, pp. 77-91, 1952.

[2] V. Piljak, "Essays on the Co-movement Dynamics of Frontier /Emerging and Developed Financial Markets". ACTA WASAENSIA 281 Business Administration 113 Accounting and Finance, 2013.

[3] H. Grubel, "Internationally diversified portfolios: welfare gains and capital flows", American Economic Review, vol. 58, No. 5, 1299- 1314, ,1968.

[4] H. Levy, and M. Sarnat, "International Diversification of Investment Portfolios", American Economic Review. Vol. 60, No. 4, pp. 668-675, 1970.

[5] M. A. King, and S. Wadhwani, "Transmission of volatility between stock markets", Review of Financial Studies, Vol. 3, No. 1, pp.5-33, 1990.

[6] K, Li, A. Sarkar, and Z, Wang, "Diversification Benefits of Emerging Markets Subject to Portfolio Constraints" Working Paper No. UBCFIN99-5; Sauder School of Business Working Paper. Available at SSRN: https://ssrn.com/abstract=272928 or http://dx.doi.org/10.2139/ssrn.272928.

[7] M.E. Hanna, J.P. McCormac, and G Perdue, A nineties perspective on international diversification. Financial Services Review Vol. 8, pp. 37 45, 1999.

[8] C. Kearney, and B.M. Lucey, "International equity market integration: Theory, Evidence and implications", International Review of Financial Analysis Vol. 13, pp. 571-583, 2004.

[9] P. L. Chelley-Steely, "Modeling equity market integration using smooth transition analysis: A study of Eastern European stock markets", Journal of International Money and Finance, Vol. 24, pp. 818-831.

[10] A. Oehler, M. Rummer, and S. Wendt, "Portfolio Selection of German Investors: On the Causes of Home-biased Investment Decisions", Journal of Behavioural Finance. Vol. 9, No.3, pp. 149-162, 2008.

[11] M. Kilka and M. Weber, "Home bias in international stock return expectations", Journal of Psychology and Financial Markets, Vol 4 , No. 3, pp. 24-41, 2000

[12] F. Abid, M. Mroua, and W. Wong, "Impact of option strategies in financial portfolios performance: Mean-variance and stochastic dominance approaches", Finance. Vol., 23, pp. 503-526.

[13] N. Katzke, "South African Sector Return Correlations: using DCC and ADCC Multivariate GARCH techniques to uncover the underlying dynamics", Working paper, No. 17/2013.

[14] R. Engle, "Dynamic Conditional Correlation: A simple class of multivariate generalized autoregressive conditional heteroskedasticity models," Journal of Business \& Economic Statistics, American Statistical Association, Vol. 20, No. 3, pp. 339-50, 2002.

[15] F. Longin, and B. Solnik, "Extreme Value Correlation of International Equity Markets", The Journal of Finance. Vo. 56. Pp. 649 - 676.

[16] S. J. Kim, F. Moshirian, and E. Wu, "Evolution of international stock and bond market integration: Influence of the European Monetary Union". Journal of Banking and Finance, Vol. 30, 1507-1534, 2007.

[17] D. Bessler and J. Yang, "The structure of interdependence in international Stocks Markets" Journal of international money and Finance, Vol. 22, No. 2, pp. 261-287, 2003.

[18] M. Graham, J. Kiviaho, and J. Nikkinen, "Integration of 22 emerging stock markets: a three-dimensional analysis", Global Finance Journal, Vol. 23, No. 1, pp. 34-47, 2012.

[19] R. M. Yusof, and M.S.A Majid, "Who moves the Malaysian Stock Market-the US or Japan? Empirical evidence from the pre-, during, and post-1997 Asian Financial Crisis", International. Journal of Business, Vol. 8, pp. 367-406, 2006.

P. Jorion, and E. Schwartz, "Integration vs. segmentation in the Canadian stock market". Journal of Finance, Vol. 41, No. 3, pp. 603 614, 1986.

[20] P. Narayan, R. Smyth, and M. Nandha, "Interdependence and dynamic linkages between the emerging stock markets of South Asia", Journal of Accounting and Finance, Vol. 44, pp. 419-439, 2004.

[21] J. Xiang, S. Wang, and J. Hao, "The Testing Method of the CoMovement of A+H Stock Prices", Modern Applied Science, Vol. 3, No 5, 2009.

[22] P. Poldauf, "International Stock Market Co-movements and The Global Financial Crisis", 2011.

[23] N. Barberis, A. Shleifer, and J. Wurgler, J., "Comovement" Journal of Financial Economics, 75, 283-317, 2005.,

[24] A. Charpentier, E. Galariotis, and C. Villa, Category-Based Tail Comovement, 2009. 
[25] P. H. Chour, P. H; Hob, and K.C. Ko, "Do industries matter in explaining stock returns and asset-pricing anomalies?" Journal of Banking and Finance, 2012.

[26] S. Cheng, "Institutional Ownership, Retail Trading and Stock Return Comovement", 2013.

[27] J. Baffes, "More on the Energy/Non-Energy commodity price link" World BankPolicy Research Paper Series, No. 4982. 2009.

[28] P. Alagidede and J.O. Mensah, J.O., 2016, "How are Africa's emerging stock markets related to advanced markets? Evidence from copulas". Econ. Model. Vol. 60, pp. 1-10, 2016.

[29] K. Wang, Y.H Chen, and S. W. Huang, "The dynamic dependence between the Chinese market and other international stock markets: time-varying copula approach" Int. Rev. Econ. Financ. Vol. 20, No. 4 pp. 654-664, 2011.

[30] K.L. Lee, "Convergence and interdependence between ASEAN-5 stock markets". Math. Comput. Simulat. Vol. 79, pp. 2957-2966, 2009.

[31] G. Lee, and J. Jeong, "An investigation of global and regional integration of ASEAN economic community stock market: dynamic risk decomposition approach", Emerg. Mark. Financ. Tr. Vol. 52, No 9, pp. 2069-2086, 2016.

[32] M. Shrestha, "Time varying conditional correlation between stock and bond returns: Evidence from CIVETS nations", 2014

[33] T. Bollerslev, "Modeling the coherence in short-run nominal exchange rates: A multivariate generalized approach," Review of Economics and Statistics, Vol. 72, No. 3, pp. 498-505, 1990.

[34] L. Cappiello, R. Engle, and K. Sheppard, "Asymmetric dynamics in the correlations of global equity and bond returns" Journal of Financial Econometrics, Vol. 4, pp. 537-572, 2006.

[35] G.S Uddin, A.M. Mohame, and A. K Tiwari, "Co-movements between Germany and International Stock Markets: Some New Evidence from DCC-GARCH and Wavelet Approaches" IPAG Business School 184 Working paper 2014-143, 2014.

[36] E. Kambeu and Z. Chikaza, "Comovement of Assets Returns between single and dual listed firms within a single stock exchange ", Journal of finance and accounting, Vol. 4, Nol. 5, pp. 262-270, 2016.

[37] T. Brannstrom, "A Study of Excess Comovement on the Swedish Stock Market”, Master's Dissertation, Dep. Of Economics, Lund University, 2005.

[38] A. Rua, and L.C Nunes, "International co-movement of stock market returns: A wavelet analysis", Journal of Empirical Finance, Vol. 16, No. 4, pp. 632-639, 2009.

[39] G. De Nicolo and M.L Kwast, "Systemic risk and financial consolidation: Are they related?," Journal of Banking \&Finance, Vol. 26, pp. 861-880, 2002.

[40] D. Das, P. Bhowmik, and R. K. Jana, (2018). A Multiscale analysis of the stock return co-movement and spillovers: Evidence from Pacific developed markets. Physica, 502, 379-393, 2018.

[41] Ghana Statistical Service report, 2010.

[42] Acquah-Sam, E. \& Salami, K. (2013). Knowledge and participation in capital market activities: The Ghanaian Experience, International Journal of Scientific Research in Education, 6(2), 189-203.

[43] B. Seidu," "Ghana Stock Exchange now 3rd largest. Correlation Analysis" Retrieved on April, 2020 from http://www.modernghana.com/news/342787/1/g hana-stockexchange-now-3rdlargest. html.

[44] C.M Jarque, and A.K. Bera, "Efficient tests for normality, homoscedasticity and serial independence of regression residuals". Economics Letters, Vol. 6, No. 3, pp. 255-259, 1980.

[45] S. Dajčman, and M. Festić, "Interdependence between the Slovenian and European Stock Markets-A DCC-Garch Analysis" Economic Research-Ekonomska Istraživanja, Vol. 25, No. 2, pp.379 395, 2012

[46] C. Brooks, "Introductory econometrics for finance. Cambridge university press", 2014

[47] B. Mandelbrot, "The Variation of Certain Speculative Prices", The Journal of Business, Vol.36, No. 4, pp. 394-419, 1963.

[48] G. M. Ljung, and G.E., Box, "On a measure of lack of fit in time series models", Biometrika, Vol. 65, No. 2, pp.297-303, 1978.

[49] S. Johansen, "Statistical Analysis of Cointegration Vectors" Journal of Economic Dynamics and Control, Vol. 12, pp. 231-254, 1988.

[50] J. M. Lebo, and J.M Box-Steffensmeier, "Dynamic conditional correlations in political science" American Journal of Political Science. 52(3): pp. 688-704, 2008.

[51] A. Silbennoinen, and T. Terasvirta, "Multivariate GARCH models", No 669, SSE/EFI Working Paper Series in Economics and Finance from Stockholm School of Economics, 2.

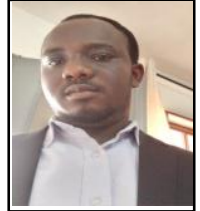

Thomas Appiah is a $\mathrm{PhD}$. Candidate with UNICAF University, Malawi, and currently holds an M-phil degreee in Finance from the Kwame Nkrumah University of Science and Technology and a bachelor's degree in Economics from the University of Ghana. He is currently a lecturer with the department of accounting and Finance, Ghana Technology University College.

He has published in several international journals and also attended a number of local and international conferences. His research interest is in the areas of financial technology and innovation, financial markets, and SMEs financing.

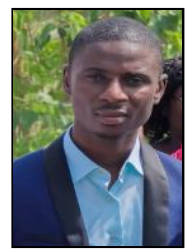

Abednego Forson holds M-phil degree in finance and MBA degree also in finance all from the Kwame Nkrumah University of Science and Technology, Kumasi and a Bachelor of Science degree in Accounting from the Central University, Accra, Ghana.

His research interest is in the areas of financial institutions and financial market. 